\title{
Future Employability Skills Sets for Manufacturing Industries
}

\author{
Mohamad Sattar Rasul ${ }^{1}$, Rose Amnah Abd. Rauf ${ }^{2} \&$ Ahmad Rosli Mohd Nor $^{1}$ \\ ${ }^{1}$ Faculty of Education, Universiti Kebangsaan Malaysia (UKM), Bangi, Selangor, Malaysia \\ ${ }^{2}$ Faculty of Education, University Malaya, Kuala Lumpur, Malaysia \\ Correspondence: Mohamad Sattar Rasul, Faculty of Education, Universiti Kebangsaan Malaysia (UKM), \\ Bangi 43600, Selangor, Malaysia. E-mail: drsattar@ukm.my
}

Received: March 31, 2014 Accepted: August 6, 2014 Online Published: September 28, 2014

doi:10.5539/ies.v7n10p138 URL: http://dx.doi.org/10.5539/ies.v7n10p138

\begin{abstract}
Employability skills are important skills that employers emphasis on graduates. Lack of these skills will cause the career development of an individual as well as the industry productivity. This study aim was to elicit views of 30 employers in the manufacturing industries on employability skills individuals in the workplace focusing on the future needs. This research used individual interviews with employers and discussions of focus group. A comprehensive, open-ended questionnaire used was developed after discussions with the panel of experts in the focus group. Findings from the interviews indicated that employers emphasis different levels of skills for different jobs. Employers need employees with strong interpersonal skills such as communication skill, problem solving skills, team work and entrepreneur skills which related to the context of working environment. Employers also suggest that project oriented and work process oriented is the best method to inculcate these skills.
\end{abstract}

Keywords: employability skills, future skills, project oriented, work process oriented, focus group, experts

\section{Introduction}

Advancement in technology requires workforce with higher talent and skills from industry. According to Taylor (2005), when the total number of low skilled workers is very big in a developing country, the country is not ready to have an industrial-based economy. The needed changes also would influence the demand for skilled workers.

The theory of human capital define, "employability" is an individual ability and to success in career and develop one career beside his/her special skills (Fugate et al., 2004).Human capital development is an effort to achieve cost savings and improve the performance of the industry. Schultz (1963) defined human capital as an important element for upgrading company performance and to improve productivity of employees and sustainability to be more competitive. However, the cost of developing human capital is increasing; with these, employers expect educational institutions to developed graduates employability skills as required by the labor market to reduce additional training on graduates' employability skills by industry.

Last two decades, studies underscores them criticality (Askov \& Gordon, 1999) and are transferable skill that enabling knowledge, skills, and attitudes required in the work place of 21st century (SCANS, 1991).

Therefore, graduates with employability skills will have an advantage in getting jobs in the industry. The institutions of education must produce graduates with high non-technical skills (Husain, Mokhtar, Ahmad, \& Mustapha, 2010).Therefore identifying indicators for employability skills from the employer's perspective is crucial for instructors and student to understand and inculcate the employability skills.

An impact study on teaching and learning employability skills showed that the skills is hard to be developed in classrooms (Cranmer, 2006). Recent developments in competence-based showed that learning and teaching in workplace is the best practices to develop graduates employability skills but then it has been a problem for decades to link between learning and work. (Wesselink, Jong, \& Biemans, 2009).

\subsection{Problem Statement}

Employability skills issue is something that has not been settled. Employability skill is the ability of non-technical and occupational skills that are just as important as technical skills (Ramlee, 1999). In 2008 Malaysian Ministry of Higher Education (MOHE, 2009), identified that 35 percent $(4,616)$ out of 13,002 
technical undergraduates were unemployed. Meanwhile issues in UK from study on the impact of employability skills teaching and learning on graduate labour market prospects showed that a "mismatch" of the skills acquired at university and the skills needed by employers Cranmer (2006).

Ramlee (2002) on his research on Malaysian graduates and Kathleen (2005) on her research in United States found that employers dissatisfied with the graduates interpersonal skills. So as Fitrisehara et al. (2009) regarding the employability skill of graduates, showed moderate level and more importance is that there is a significant differences of the skills inculcated with the students' field of studies. Zaini (2005) found that 80.000 technical graduates who are still unemployed, are too depending on academic qualifications and less of the non-technical ability which employers required most.

To ensure opportunities to get employment and sustainability of work graduates should able to development new skills and adaptation to changes (Australian Council for Educational Research, 2008; Kearns, 2001). Appropriate curriculum design to integrate employability skills in institutions is a key factor to improve graduates employability skills ability. Mismatch of employability skills will occur when the integration is not done appropriately. Thus, this study would like to explore the skills needed from employer's perspective to provide the indicator for instructors and student to understand and emphasis employability skills.

\section{Methodology}

This research used focus group discussions and interviews with employers. A comprehensive, open-ended questionnaire used was developed after discussions with the panel of experts in the focus group. 30 employers were selected from different type of manufacturing industry and grouped into five type of manufacturing industry which was: transport equipment (TE), machinery and equipment (ME), metal based products (MB), electrical and electronic product (E \& E), and other product based industry (OT). Employers participating in this research were Operational Manager, Supervisor and Chief Executive.

Technique used to probe the future indicators of the employability skills needed from the employers are using Delphi Technique. There are four phase; 1) Identify the future employability skills indicators from employers by interviews; 2) Developed an instrument (questionnaire) by extracting from the interviews transcribe and discuss what's important and what's not important with expert panel; 3) Improve the indicators and test it out again and 4) Full consensus acquired.

Throughout the Delphi Technique, a thematic data analysis was carried out to identify the employability skills indicators from the employers' comments. A constant thematic analysis was done to code the skills before creating the basic theme and main theme of the employability skills.

\section{Findings}

In this section of paper, result from the employer's interviews will be presented. From the employer's interviews, emphasis on employability skills should be based on the different level of jobs.

\subsection{Personal Values}

Through this study, it was found that emphasis was given to the following personal values by the employers:

- Responsibility to job.

- Self-esteem and maintain positive.

- Sociability.

- Honesty and high integrity.

- Commitment and work hard towards goal.

- Adaptability to working environment.

Employers expressed the need to have a range of personal values, irrespective of their academic qualifications or experience. These values are considered as a contribution to create a harmonize and productive workplace environment which in turn will encourage good relations with clients. As for the aspect of "adaptability and flexibility", the ability to adapt the workplace situation is essential because it involved so many person in the organization (Clarke, 1997); Verhaar and Smulders (1999) stated that employers need flexible workers which able to cooperate and work with different cultures.

The main personal qualities that were mentioned by employers are good personal values beside their technical skills. Employers are looking for employees who can be trusted, featuring standards of ethical conduct in organizations, themselves and others. Highlighted certain personal attitudes and required by companies, such as working hard towards the goal of achieving and displaying a high level of concentration. Employers see that students with high self-esteem are important. Many employers in the manufacturing industry mentioned that 
assert themselves in social situations is important. Employees must show friendliness, understanding empathy and decency in group work. Contextual changes, such as adaptability, loyalty, purity, reliability and physical fitness also affects personal qualities. For example, a manager of the company noted that new employees must be open to change and new information and unexpected obstacles. The industry needs people who are loyal to the industry, have the desire to work and be reliable.

\subsection{Interpersonal Skills}

Among the employability skills, interpersonal is considered as the most important skills. It consist of communication, teamwork skills and problem solving skills.

\subsubsection{Communication Skill}

Research done by Field (2001) and McLeish (2002) stated that communication skills in technical context are different from the non-technical communication skills. Employees need to communicate through a wide variety of communication skills such as presentations, reporting to project teams, and ensuring team members understand the projects delivered is very important.

The overall concept of communication can be verbal and non-verbal depending on situation of work process. From the interviews employers sees communication skills as:

- Able to read and interpret written information in documents (etc. manuals, graphs, and schedules).

- Able to write to communicate messages, thoughts, ideas, and information.

- Able to listen and respond to verbal messages and body language.

- Able to speak and participate in conversation, discussion, and group meeting.

Results from these studies shown that in many manufacturing industry contexts, communication is aimed to support everyday operations and team development. The capacity to establish rapport, involve close personal contact between customers. Employees who have good ideas need to be able to communicate them effectively or else there is no value. In some cases of communication skill, report writing is most necessary where employers mentioned that we need employees that can write a good report that can convince others. Young engineers must acquire high skills in producing documentation for tender. Another important aspect of communication skills are interpret manuals and written information such as graphs, manuals, and schedules to perform tasks and relaying information via writing. To be able to interpret information from supervisors or boss is very important and necessary as one of the employers mentioned. More generally, employers across a range of manufacturing industries mention that employees without adequate communication skills are difficult to do their jobs. According to one employer 'communication in project team and everyday operations team is what we want' and 'graduates are advice to talk to a all range of employees in the company'.

Employees in manufacturing industry should also work and respond appropriately under considerable time and determine what the requirements are quickly. Employers stressed that the need of employees to have good listening skills together with their verbal skills. Listening in manufacturing industry is important for giving and receiving feedback, in order to understand the requirements. One needs to listen in order to find out the best way to fulfill the assignment required.

\subsubsection{Team Work}

Employers felt that team work were extremely important. It is mentioned that no position in the industry that did not require elements of teamwork. Team work is also considered as a critical success factor for an employee. To understand age factors, gender, culture is the best way to achieve an effective team working (Alston et al., 2009).

From the analysis, the following team work skills should be emphasized by graduates:

- Play a part as a team member: Works supportively with others and contributes with suggestion, ideas, and effort to others.

- Guiding/Coaching team members: help others in learning necessary knowledge and skills.

- Discussion: Discuss with team members and exchanging specific resources.

- Work with variety cultural: Works fine with multi-ethnic, different social or educational backgrounds.

Some employers from the interviewed emphasized that employees must perform the following teamwork skills, always take an active part and be able to work with others and consistently provide information, suggestions and ideas to contribute to the team. Employees must also be able to share knowledge and skills with team members and always respect and encourage each other as group discussions conducted almost every day and focus on the development of the project. As multi-racial country employers mentioned that they need employees who can work effectively and harmoniously with diverse racial, social or educational background is different. 
Employers also mentioned that employees in manufacturing industry are expected to be collaborative and participative. New employee normally will work with seniors in a project. It is important for them to be able to cooperate as a team. Most of the production work is a teamwork project. A typical team usually consists of senior manager, and several technicians who involve senior and junior who execute the work.

\subsubsection{Problem Solving Skills}

Problem solving skills were the knowledge gained from useful information to enable a person to discuss certain topics and to make conclusion. Problem solving skills required would vary according to types of problem and the complexity of the job that employees would encounter (Emery, 1999).

From the interviewed, employers indicated problem solving skills were essential for both entry level and existing employees. An employee with sound problem solving skills according to the employers could demonstrate:

- Creative/Innovative Thinking to Generates new ideas.

- Decision making in choosing best alternatives.

- Problem solving in able to identify and analyses problems.

- Seeing Things in the Mind's Eye which being able to visualize and interpret various type of information.

Comments made by the employer, including many workers have difficulty in identifying new ideas and make connections between related ideas or reshaping goals. Employers really need someone who is creative and recognizing problems as it is important in the manufacturing industry. Employees must have the skills and planning and develop alternative ideas to correct these problems. Employer are always looking for employees who can demonstrate the ability to organize and interpret the symbols, pictures, graphs, objects, and other information accurately.

Employees who can evaluate alternative ideas carefully and propose solutions are an employer of choice. Initiative in problem solving must be shown by employees rather than rely on others. All employers need employees that can resolve problems and create a good outcome.

\subsection{Entrepreneurial Skills}

Entrepreneurial Skills' encompasses such things as business opportunity to achieve goals, work independently, assembling resources, negotiates, time management, and adapting to cope with unanticipated circumstances (McLeish, 2002). Employers gave the following examples of these skills set:

- Able to identify business opportunity.

- Ability to work with minimal or without supervision.

- Managing resources.

For industries to grow in the new market is the reason to identify this area of skill. New services and products need to be produced in order to compete in current markets. In developing the business or new approaches from the employers interviewed suggested that industries relied not only on managers and specialists. The initiative should be taken by collective effort from everyone in the industry.

According to Godfrey (1997) student should be exposed to the entrepreneur skill (financial management and business studies) these skills should be included in program to encourage students involved in business. Comment on entrepreneurial skills employers is that they require an employee can contribute more than a potential business idea and can work with minimal supervision but perform. Managers and employees need to manage time effectively and reduce the process time and how to save money. Employees also must have initiative to be able to work independently and without constant supervision. They need employees that can work independently and can complete projects given on time as well as save budget but quality standards and priorities to achieve project outcomes must be well kept.

\subsection{Technology Skills}

Technology in manufacturing industry is going through rapid changes with new technologies in all aspects of production (Taylor, 2005). The application of technology to perform tasks among employees who serve in the production field is very significant as contemporary industries used various latest technologies to simplify works. Bunn and Stewart (1998) stated that technical board members agreed with the fact that the skills to use technologies are crucial in the industry. Other than that, De Leon and Borchers (1998) noted that employers mentioned that the application of technologies to carry out duties is highly required. Comments made by the employer to give the impression that technology skills are crucial. Employer's need workers at least understand the procedures for operating machines, including computers and their programming. Employees also need to 
know how to choose the procedures, equipment and machinery to be used. Employees in a plant environment may need to be familiar and specialised in preventative maintenance requirements because company emphasis on maintaining technology to solve problems in machines and other equipment. It is an advantage if employees have good or basic computer skills. Basic technology skills are fundamental to employment. Reliance on technology is increasing. It is important to understand in order to maintain the system. This caused each manufacturing process using current technology and it is constantly changing and workers need to find those skills very quickly. Thus, employers insist on new and existing employee to use technology to benefit the business. Employers suggest it would be necessary for employees to:

- Select and applies technology related to task.

- Have basic computer skills.

- Maintain technology.

\subsection{Informational Skills}

Ability to organizes and maintains information are widely used in works. According to Zolingen, Streumer, Klink, and Jong (2000) stated that the key to successful work is the ability to protect information.

Employers gave the following examples of these skills set:

- Acquire relevant information from various sources.

- Manage acquired information.

- Share ideas and willing to share new ideas.

- Learn Independently.

Employers explain that they need employees who have the ability and knowledge to obtain relevant information from multiple sources, identifying the need for data, obtain it from the resources of the existing or create, and evaluate the appropriateness and accuracy. Workers must constantly analyze and integrate information obtained with its own ideas, organize, process, and maintain written or computerized records and other forms of information in a systematic way. Choose and analyze information and communicate the results to others using oral, written, graphic, image, or multi-media methods is necessary. Employees need to know how to show the ability to learn independently with minimum supervision and does not require consistent monitoring. It is an advantage for employees to develop this skill learns ways of keeping and protecting information.

\subsection{Leadership Skills}

Key leadership behaviors identified by employers were confidence, initiative and teamwork. Leadership is also about full and ongoing accountability, the capacity to work autonomously. Behaviors that show this skill are:

- Able to lead team members.

- Able to motivate team members.

- Able to resolve conflict.

- Taking responsibility for themselves and others.

All of the employers emphasized the importance of leadership throughout the organization compared to traditional organisations, where leadership is typically associated with people at senior levels. Many companies reflected that the changes of the last decade that had led to flatter organisations and team approaches to work meant the need for the individual employee to take on leadership roles throughout all levels of the enterprise. Industries spoke of the desire for employees to show leadership skills both formally and informally in the workplace.

When asked to describe the skill of leadership, many interviewees referred to such things as influencing others, standing up to drive improvement, creating movement, challenging boundaries in the words of one interviewee, 'a state of mind focused on going out and managing change'. Employees with good leadership skills are able to assume leadership role in assigning tasks and have strongly influence, motivate and inspire an individual or a team, and offer ample constructive solutions to resolve conflicts based on objective criteria. One of the most leadership skills required by employers is that when an employee is given a task, they needs to see it though from beginning to end, to take responsibility, and to be accountable.

\section{Conclusion}

The results of these findings can be useful as a guide for technical instructors or lecturer to plan which employability skill should be emphasis, and considered important to be acquired by students before working in the industry. The findings also can be useful to graduates or job seekers in the manufacturing industry to be prepared at the expectation of these employers. 
In this study, the findings showed that employers from manufacturing industries place employability skills as a must be owned by all new employees and graduates to enable them to compete in the global market. Therefore it is suggested that the authorities of education institution should enhance the important employability skills either through the professional development of lecturers, curriculum and co-curriculum. Apart from that, programs should carry out real working environment for students to be able to understand employability skills better. These will serve the purpose to make students realized that employability skill is very important to them to perform.

\section{References}

Alston, A. J., Cromartie, D., Wakefield, D., \& English, C. W. (2009). The importance of employability skills as perceived by the employers of united states' land-Grant College and university graduates. Journal of Southern Agricultural Education Research, 59, 56-69.

Askov, E. N., \& Gordon, E. E. (1999). The brave new world of workforce education. New Directions for Adult and Continuing Education, 83, 59-68. http://dx.doi.org/10.1002/ace.8305

Australian Council for Educational Research (ACER). (2008). Graduate Skill Assessment. Summary report. Canberra: DETYA, Higher Education Division.

Bunn, P. C., \& Stewart, L. (1998). Perceptions of Technical Committee Members Regarding the Adoption of Skill Standards in Vocational Education Programs. Journal of Vocational and Technical Education, 14, $1-14$.

Clarke, A. (1997). Survey on employability. Industrial and Commercial Training, 29, 177-183. http://dx.doi.org/10.1108/00197859710178737

Cranmer, S. (2006). Enhancing graduate employability: Best intentions and mixed outcomes. Studies in Higher Education, 31(2), 169-184. http://dx.doi.org/10.1080/03075070600572041

De Leon, J. E., \& Borchers, R. E. (1998). High School Graduate Employment Trends and the Skills Graduates Need to Enter Texas Manufacturing Industries. Journal of Vocational and Technical Education, 15, 1-19.

Emery, J. H. (1999). The Employability Skills Discourse: A Conceptual Analysis of the Career and Personal Planning Curriculum. Conceptual Analyses of CAPP.

Field, L. (2001). Skill Requirements of Leading Australian Workplaces. Employability Skills for the Future Project 2002 Supporting Case Study Research, Field Learning Pty Ltd.

Fitrisehara, K., Ramlah, H., \& Rahim, A. B. (2009). Employability Skills Among the Students of Technical and Vocational Training Centers in Malaysia. European Journal of Social Sciences, 9(1), 147-160.

Fugate, M, Kinicki, A. J., \& Ashforth, B. E. (2004). Employability: A psychosocial construct, its dimension, and applications. Journal of vocational behavior, 65(2), 14-38. http://dx.doi.org/10.1016/j.jvb.2003.10.005

Godfrey, M. (1997). Planning for Vocational Education, Training and Employment: A Minimalist Approach. International Journal of Manpower, 18, 206-227. http://dx.doi.org/10.1108/01437729710169346

Husain, M. Y., Mokhtar, S. B., Ahmad, A. A., \& Mustapha, R. (2010). Importance of Employability Skills from Employers' Perspective. Procedia-Social and Behavioral Sciences, 7, 430-438. http://dx.doi.org/10.1016/j.sbspro.2010.10.059

Kathleen, C. (2005). Developing Employability Skills. Regional Educational Laboratory. School Improvement Research Series (SIRS).

Kearns, P. (2001). Generic Skills For The New Economy-Review of research. Adelaide: NCVER.

McLeish, A. (2002). Employability Skills for Australian Small and Medium Sized Enterprises: Commonwealth of Australia.

Ramlee, M. (1999). The Role of Vocational and Technical Education in the Industrialization of Malaysia as perceived by Educators and Employers. Purdue University: Tesis Doktor Falsafah.

Ramlee, M. (2002). The role of vocational and technical education in the industrialization of Malaysia as perceived by educators and employers (Doctoral dissertation, Purdue University).

SCANS. (1991). Skills and Task for Jobs.A SCANS Report for America 2000. Washington, D.C.: U.S. Department of Labour.

Schultz, T. W. (1963). The Economics Value of Education (3rd ed.). New York and London: Columbia University 
Press.

Taylor, A. (2005). What Employer Look For: The Skills Debate and The Fit With Youth Perceptions. Journal of Education and Work, 18(2), 201-218. http://dx.doi.org/10.1080/13639080500085984

The Ministry of Higher Education of Malaysia (MOHE). (2009). Seminar on Employability: An Overview of Graduate Employability of Recent Graduates: Some Facts and Figures. Putrajaya, Malaysia.

Verhaar, C. H. A., \& Smulders, H. R. M (1999). Employability in Practice. Journal of European Industrial Training, 23, 268-274. http://dx.doi.org/10.1108/03090599910284605

Wesselink, R., Jong, C., \& Biemans, H. J. A. (2009). Aspects of Competence-Based Education as Footholds to Improve the Connectivity Between Learning in School and in the Workplace. Vocations and Learning, 3(1), 19-38. http://dx.doi.org/10.1007/s12186-009-9027-4

Zaini, A. (2005). Students and Employers as Customers of Multimedia College. Proceedings of National Seminar "The development of Technology And Technical-Vocational Education And Training In An Era of Globalization: Trend and Issues". Kuala Lumpur.

Zolingen, S. V., Streumer. J., Klink, M. R., \& Jong, R. D. (2000). Implementing a new model for on-the-job training: Critical success factors. International Journal of Training and Development, 4(3), 208-216. http://dx.doi.org/10.1111/1468-2419.00108

\section{Copyrights}

Copyright for this article is retained by the author(s), with first publication rights granted to the journal.

This is an open-access article distributed under the terms and conditions of the Creative Commons Attribution license (http://creativecommons.org/licenses/by/3.0/). 